\title{
A computational simulation of long-term synaptic potentiation inducing protocol processes with model of CA3 hippocampal microcircuit
}

\author{
D. Świetlik¹, J. Białowąs², A. Kusiak³ , D. Cichońska ${ }^{3}$ \\ ${ }^{1}$ Intrafaculty College of Medical Informatics and Biostatistics, Medical University of Gdansk, Poland \\ 2Department of Anatomy and Neurobiology, Medical University of Gdansk, Poland \\ ${ }^{3}$ Department of Periodontology and Oral Mucosa Diseases, Medical University of Gdansk, Poland
}

[Received 17 February 2018; Accepted: 23 April 2018]

\begin{abstract}
An experimental study of computational model of the CA3 region presents cognitive and behavioural functions the hippocampus. The main property of the CA3 region is plastic recurrent connectivity, where the connections allow it to behave as an auto-associative memory. The computer simulations showed that CA3 model performs efficient long-term synaptic potentiation (LTP) induction and high rate of sub-millisecond coincidence detection. Average frequency of the CA3 pyramidal cells model was substantially higher in simulations with LTP induction protocol than without the LTP. The entropy of pyramidal cells with LTP seemed to be significantly higher than without LTP induction protocol $(p=0.0001)$. There was depression of entropy, which was caused by an increase of forgetting coefficient in pyramidal cells simulations without LTP $(R=-0.88, p=0.0008)$, whereas such correlation did not appear in LTP simulation ( $p=0.4458$ ). Our model of CA3 hippocampal formation microcircuit biologically inspired lets you understand neurophysiologic data. (Folia Morphol 2018; 77, 2: 210-220)
\end{abstract}

Key words: learning and memory, hippocampus, long-term synaptic potentiation, forgetting, theta rhythm, computer simulation

\section{INTRODUCTION}

The modular structure of hippocampus may lead to a hypothesis that every area subserves specific computational functions, which results in development of various theories about the function of each subfield [52]. The CA3 area is believed to act as an auto-associative memory; however, DG's main take is probably producing internal representations which are infrequent and orthogonal.

Models of associative memory mostly rely on auto-associative networks [57] and discrete attractors ones, examples of which may include Marr [23] and McClelland et al. [24], Treves and Rolls [52], O'Reilly and McClelland [35], Hasselmo et al. [15] and Shastri [44]. On the contrary, models for spatial learning ale typically based on continuous attractor networks used to reconstruct experimental outcomes such as place field information $[3,9,18,41]$.

Misják et al. [26] introduced examples of hippocampal standardised models associated with spatial and episodic type of memory. They used a rate unit to evolve a model for the CA3 and thankfully to the Bienenstock et al. [5] learning rule, they could expose place cell properties, which can be used for preserving episodic memories. Rolls et al. [38] improved the model based on a consolidated attractor network. They were also using rate units, which are able to reserve both discrete and continuous representa- 


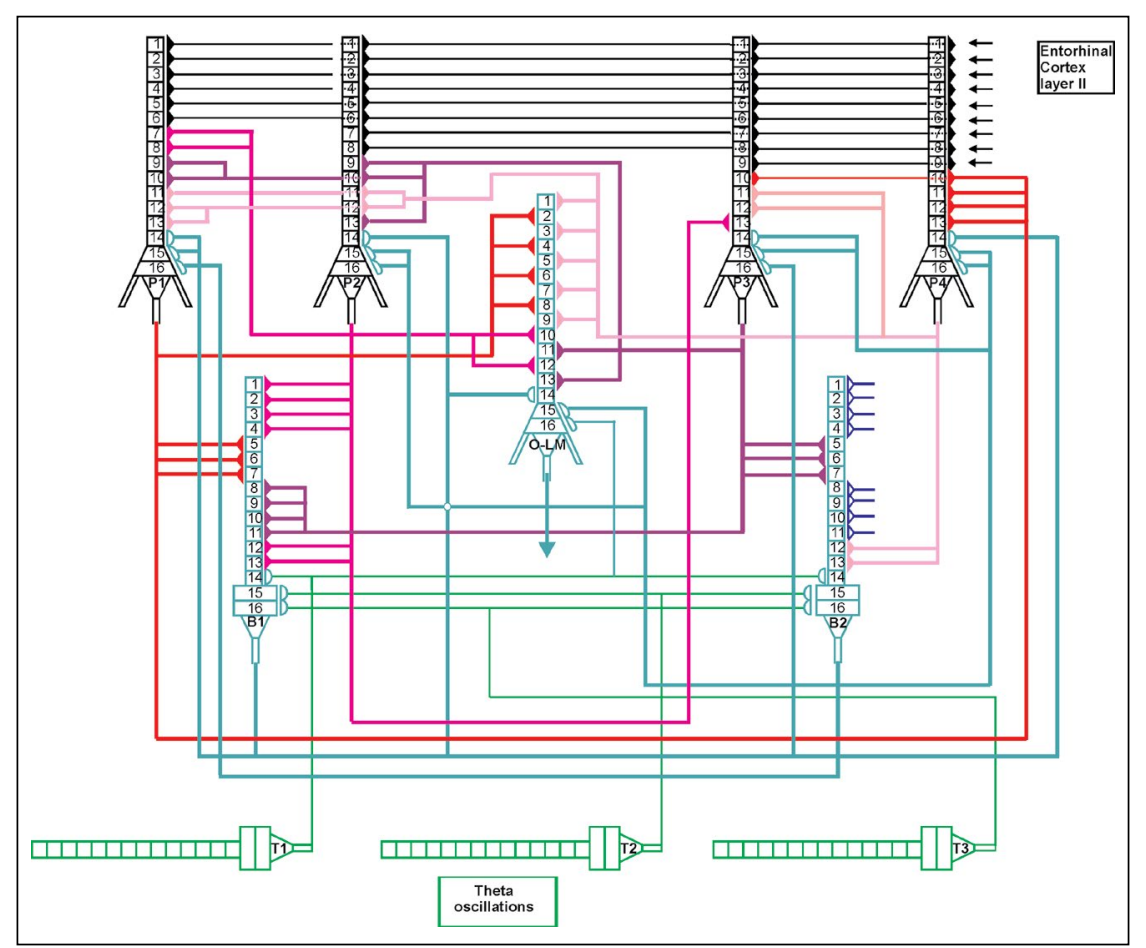

Figure 1. Hippocampal formation CA3 microcircuit showing pyramidal, basket and OL-M cells. CA1 network: P1, P2, P3, P4 — pyramidal cells; B1, B2 - basket cells and OL-M cell. Each CA3 pyramidal cell received excitation from the layer 2 entorhinal cortex.

tions. There are even more teams working on a "Spiking Model of Hippocampus for Guiding Behaviour" project, like Hasslemo's, Eichenbaum's and Robert Cannon's group [13].

It has been proved that mossy fibres demonstrate a variety of long-term synaptic vividness containing assocional and N-methyl-D-aspartate (NMDA) independent form of long-term depression and potentiation (LTD and LTP) [6]. However, experiments with rats in which mossy fibres LTP/LTD were eliminated, provided no valid effects on learning task performance [54].

\section{Hippocampal morphology - CA3 region}

Pyramidal neurons are prominent cells in CA3 region and their population in a human brain is about $230 \times 104$ and $160 \times 103$ in a rat brain [7, 47]. Pyramidal cells accept excitatory inputs from perforate path in layer II of entorhinal cortex (4000 synapses), mossy fibres from dentate gyrus (50 synapses) and recurrent connections from CA3 (12,000 synapses) [54]. Action potentials generated in the CA3 are expanded to CA1 area through the Schaffer collaterals. The only sizable connection to other subcortical areas is the bilateral connection to the lateral septal nucleus [51]. The presence of this projection suggests that the lateral septal nucleus takes part in process of learning and recall connected with CA3 associative memory model [15].

\section{MATERIALS AND METHODS}

The model describing simulation of CA3 microcircuit is presented in Figure 1. The model is built with various cell types which morphology includes the soma, axon and both apical and basal dendrites. There are four pyramidal cells (P1, P2, P3, P4), two basket cells (B1, B2) and one O-LM cell. The theta oscillation is delivered by the septo-hippocampal pathway and should be described as a frequency on the band of $4 \mathrm{~Hz}$ to $12 \mathrm{~Hz}[2,25,36,37,42,43]$ and might be temporarily anchored in faster gamma-frequency oscillations $[8,10,12,50]$. It is believed that this oscillation plays a basic role in hippocampal activity such as introduction of spatial information $[34,46]$, in-time locking cell activities and regulation of learning facilities $[11,16]$. All mathematical specifications of CA3 model neurons ale given in APPENDIX.

\section{CA3 pyramidal cells}

Every CA3 pyramidal cell consists of 16 compartments. Every dendrite has a synapse, an excitatory or inhibitory one. There are glutamate receptors for excitatory inputs: AMPA - E $(k, i), N M D A-M(k, i)$. 
GABA receptors are for inhibitory inputs: I $(k, i)$ where " $k$ " is the number of dendrite compartments and " $\mathrm{i}$ " is a number of the area register table. Each CA3 cell receives somatic synaptic inhibition from CA3 basket cells in their somas and form the CA3 O-LM cells in their stratum lucid dendrites. Excitatory inputs in stratum lucid dendrites are received from CA3 pyramidal cells, layer 2 entorhinal cortex and dentate gyrus.

\section{CA3 basket cells}

Every CA3 basket cell consists of 16 compartments. Every dendrite has a synapse, an excitatory or inhibitory one. There are glutamate receptors for excitatory inputs: AMPA - $E(k, i)$, NMDA - $M(k, i)$. GABA receptors are for inhibitory inputs: I $(k, i)$ where " $k$ " is the number of dendrite compartments and " $\mathrm{i}$ " is a number of the area register table. Excitatory connections are received to their distal dendrites form layer 2 entorhinal cortex and to medium dendrites from dentate gyrus granule cells mossy fibres. Inhibitory impulses come from connections in medial septum of their somas.

\section{CA3 O-LM cells}

In the CA3 region every O-LM cell consists of 16 compartments. Every dendrite has a synapse, an excitatory or inhibitory one. There are glutamate receptors for excitatory inputs: AMPA - E $(k, i)$, NMDA - M $(k, i)$. GABA receptors are for inhibitory inputs: I $(k, i)$ while " $k$ " is the number of dendrite compartments and " $\mathrm{i}$ " is a number of the area register table. Each O-LM cell receives excitatory and inhibitory connections. The first ones are received from the active CA3 pyramidal cells in their basal dendrites, whereas the second one is received from the medial septum.

\section{Hippocampal CA3 simulation environment}

According to Witter [see 14] the CA3 area receives inputs from entorhinal cortex layer 2 and this input for every pyramidal cell was measured as firing at a medium frequency of $42 \mathrm{~Hz}$. Each basket cell acquires input from entorhinal cortex layer 3 and dentate gyrus and a frequency of $50 \mathrm{~Hz}$ was modelled as the firing in this case. The firing average frequency for the medial septum was calculated as $8 \mathrm{~Hz}$.

\section{Synaptic properties}

There are glutamate receptors for excitatory inputs: AMPA - E $(k, i)$, NMDA - M $(k, i)$. GABA receptors are for inhibitory inputs: I $(k, i)$ where " $k$ " is the number of dendrite compartments and " $\mathrm{i}$ " a number of the area register table. Each area simulates $0.5 \mathrm{~ms}$ of earl time and primitively is filled with the resting potential of value ReP $=-80 \mathrm{mV}$. The actual value of postsynaptic potential is estimated by using (Eq. 2.12) and (Eq. 2.13), for subsequent computations from (Eq. 2.14) and (Eq. 2.15-2.17). The so called spine coincidence detector for weight changes relies on the biological mechanism of the long-term synaptic potentiation (LTP) is in the dotted circle. AMPA and NMDA are both sorts of biological receptors. Ex means excitatory, Inh - inhibitory and PSP is summarised postsynaptic potential, measured as a disparity between the sums of Ex and Inh (see APPENDIX).

\section{RESULTS}

Biologically acceptable frequencies for all input strikes were chosen on the same principles as in the papers of Bliss and Lømo [6]. The excitatory inputs which originate in the modelled mossy fibres from dentate area; 7, 8 and 9 of CA3 pyramidal cells for LTP induction were stimulated at an average frequency of $100 \mathrm{~Hz}$ for $400 \mathrm{~ms}$. There is a similarity between this examination and the one carried out by Bliss and Lømo [6] on the perforant path. The outcome of this experiment is a proof for biological plausibility of CA3 model as a mechanism related to processing of information. Figures 2 and 3 describe simulations accomplished with forgetting coefficient (FQ) from 10 to 100 . Those simulations present correlation between increased FQ and output strike-trains. The value of LTP and frequency of action-potential generation enhanced in every examined case.

In the experiments carried out with and without the LTP inducing protocol after $10 \mathrm{~s}$ of stimulation it was observed that the average frequency decreased the pyramidal cells however the FQ has increased. This phenomenon could lead to a conclusion that the LTP induction facilities the additional firing in correspondence with less valid input frequencies.

Average frequency of the CA3 pyramidal cells model was substantially higher in simulations with LTP induction protocol than without LTP $(p=0.0001)$. Very similar results were achieved for both basket and OL-M cells; indeed higher frequency $(p=0.0001)$ was observed in LTP induction protocol (Fig. 2).

The CA3 model was also examined without LTP inducing protocol and no frequency increase was proved alter the 3rd second of simulation. Without LTP cells did not fire any action potential, even if the increase at the end of the 2 nd second appeared. 


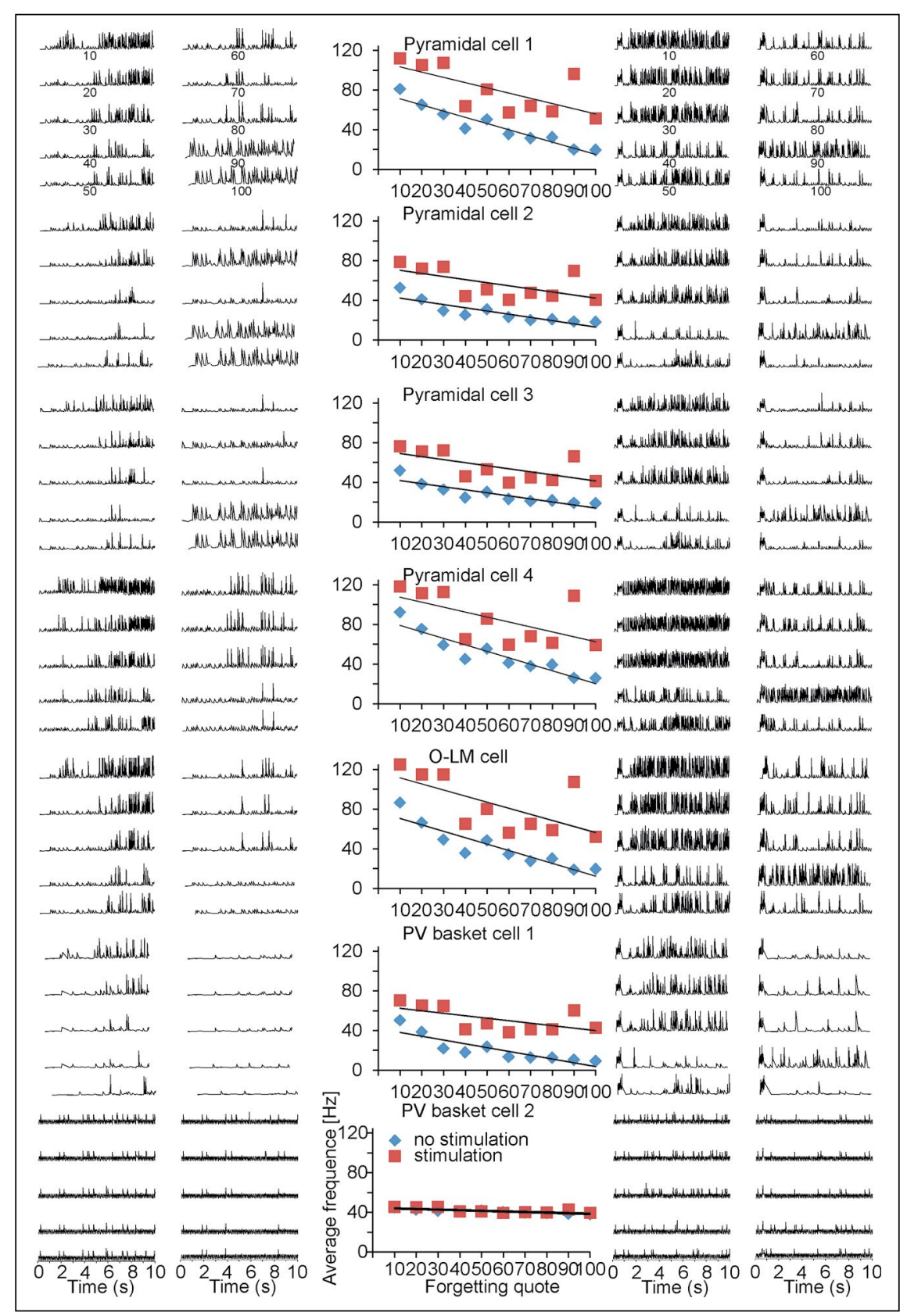

Figure 2. Basic $10 \mathrm{~s}$ real time simulation of pyramidal cells, basket cells and OL-M cell without and with long-term synaptic potentiation (LTP) inducing protocol. On the left: time course of summarised post-synaptic potential for all cells of CA3 region without LTP inducing protocol. On the right: time course of summarised post-synaptic potential for all cells of CA3 region with LTP inducing protocol. In the middle panel: correlations between forgetting coefficient 10, 20,30, 40, 50,60, 70, 80, 90 and 100 and average frequency for all modelled cells of CA3 region.

The trial without inducing LTP protocol in CA3 model presents that after 2-s duration of the experiment the increased pyramidal cells frequency stabilises at the value of $36.69(1.80 \mathrm{~Hz})$, which is very close to the most important input frequency $37.03(1.03 \mathrm{~Hz})$ planned for excitatory inputs of pyramidal cells.

The trial with inducing LTP protocol CA3 model presents that after 2-s duration of the experiment the increased pyramidal cells frequency stabilises at the value of $53.75(3.44 \mathrm{~Hz})$ which is very close to the most important input frequency $57.75(4.12 \mathrm{~Hz})$ programmed for excitatory inputs of pyramidal cells (Fig. 3).

This experiment describes a huge diversification and higher quality for coincidence detection in simulation involving LTP induction protocol. In all cases the 


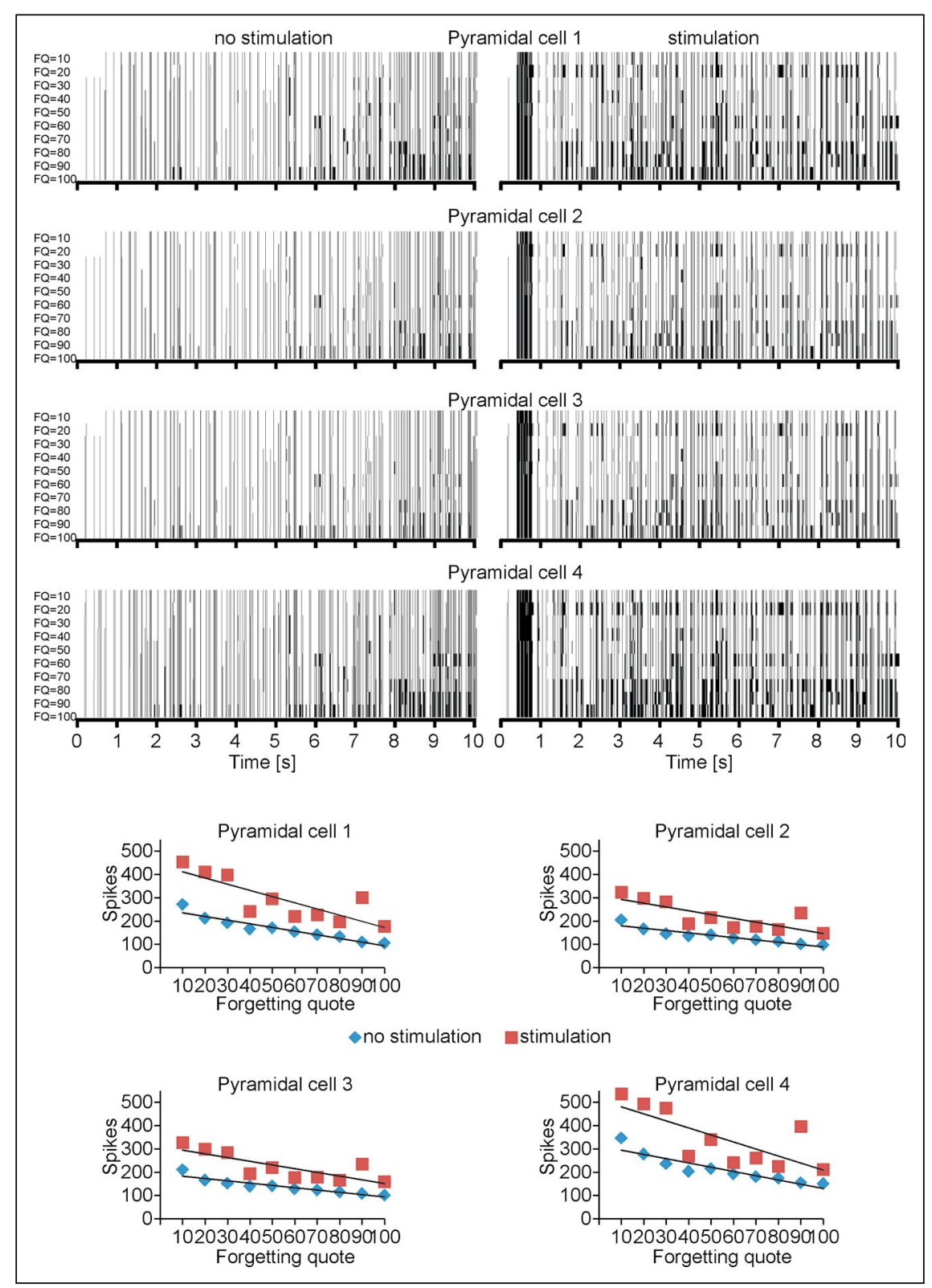

Figure 3. Basic $10 \mathrm{~s}$ real time simulation output spikes train of pyramidal cells, basket cells and OL-M cell without and with long-term synaptic potentiation (LTP) inducing protocol. On the left: output spikes train for all cells of CA1 region without LTP inducing protocol. On the right: output spikes train for all cells of CA1 region with LTP inducing protocol. On the bottom: correlations between forgetting coefficient 10, 20, $30,40,50,60,70,80,90$ and 100 and number output spikes for pyramidal cells od CA3 region without and with LTP inducing protocol.

values of LTP enhanced after the training procedure. This occurrence was observed even within the nearby synapses of pyramidal cells in connection to those which were stimulated.

A diversity of methods can be used in order to present a regular or chaotic behaviour of CA3 model and multiple neural spike train data analysis. In this paper we present the visual recurrence analysis (VRA) which was expanded by Eugene Kononov and selected from a variety of methods. The results, which are given in Figures 4 and 5, were accomplished with the forgetting coefficient 10, 20, 30, 40, 50,60, 70, 80,90 and 100. Moreover, Figure 4 describes relationship settling dimension, correlation dimension and entropy with forgetting quote with and without LTP inducing protocol.

There were no statistical differences in embedding dimension between simulation with LTP inducing protocols and without LTP $(p=0.5668)$ for pyramidal cells (Fig. 5). Similar outcome was achieved for 


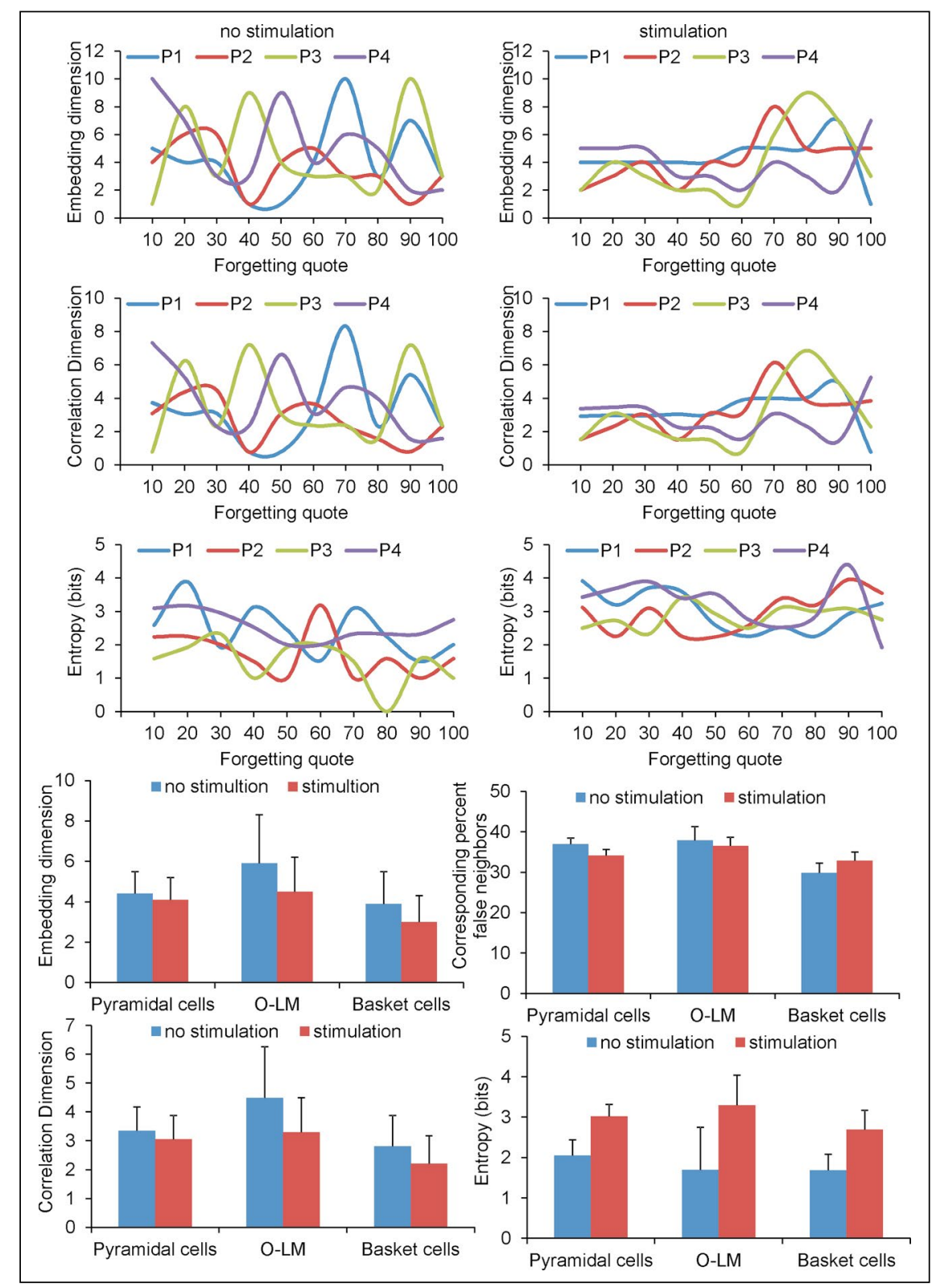

Figure 4. The recurrence result: embedding dimension, correlation dimension and entropy depending on the forgetting coefficient $10,20,30$, $40,50,60,70,80,90$ and 100 of pyramidal cells without and with long-term synaptic potentiation (LTP) inducing protocol. On the left: results without LTP inducing protocol. On the right: results with LTP inducing protocol. Histograms on the bottom show comparison embedding with regard to dimension, correlation dimension, corresponding per cent of false neighbours and entropy without and with LTP inducing protocol.

correlation dimension ( $p=0.3447$; Fig. 4). However, the entropy of pyramidal cells with LTP seemed to be significantly higher ( $p=0.0008$; Fig. 5 ).

In case of basket cells there was no statistical significance among embedding dimension $(p=0.2048)$ and correlation dimension $(p=0.1859)$ conducted with and without LTP inducing protocol. The basket cell's entropy with LTP seemed to be significantly higher $(p=0.0008)$. Examined OL-M cells presented statistical difference only for entropy, which was higher with LTP inducing protocol $(p=0.0019)$.

Results of simulation carried out with and without LTP inducing protocol proved that there is a strong interdependence among embedding dimension and correlation dimension $(p=0.0001)$.

There was depression of entropy, which was caused by an increase of FQ in pyramidal cells simulations without LTP $(R=-0.88, p=0.0008)$, whereas such cor- 


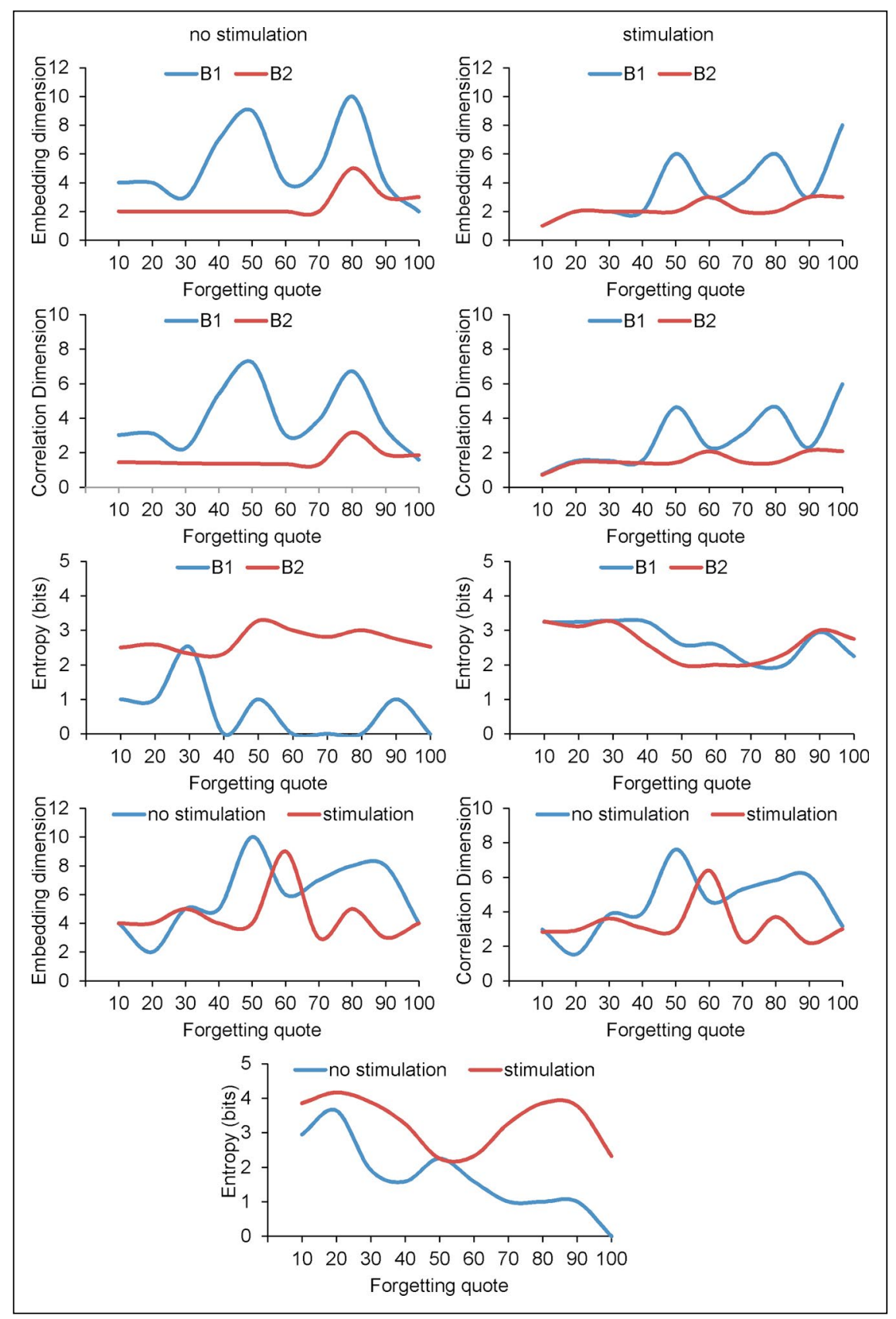

Figure 5. The recurrence result: embedding dimension, correlation dimension and entropy depending on the forgetting coefficient 10, 20,30, $40,50,60,70,80,90$ and 100 of basket and OL-M cells without and with long-term synaptic potentiation (LTP) inducing protocol. The 3 diagrams on the bottom show comparison of the results obtained without and with LTP inducing protocol for OL-M cell.

relation did not appear in LTP simulation ( $p=0.4458$ ). The same phenomenon occurred in simulation with OL-M cells. Decrease of entropy was caused by FQ increase $(R=-0.93, p=0.0001)$, whereas such correlation did not appear in LTP simulation $(p=0.1774)$. However, in case of basket cells in LTP simulation the embedding dimension $(R=0.85, p=0.0020)$ and correlation dimension $(R=0.84, p=0.0022)$ increase were related to the increase of FQ.
Such correlation for basket cells did not appear in simulation without LTP inducing protocol $(p=0.6329 ;$ Figs. 4,5$)$.

\section{DISCUSSION}

The biologically plausible modelling of learning and memory in CA3 microcircuit has been presented. CA3 formation microcircuit acts also in a manner as auto-associative memory $[39,40]$. 
Our stimulation is closely similar to the LTP-inducing protocols from the work of Bliss and Lømo [6], which describes how the short $100 \mathrm{~Hz}$ stimulation of perforant path in rabbit hippocampus can cause LTP on dentate granule cells. The presented model of CA3 hippocampal formation simulates the influence of the synaptic weights in pyramidal cells and timing of firing of different cells due to the theta rhythm in the same way as presented in $[19,20,27,48,49$, $53,55]$. We showed in our model CA3 network that excitatory and inhibitory cells modulate their output frequencies according to theta rhythm fired in phase with the trough of entorhinal cortex $[14,53,55]$.

If an action potential reaches the synapse in the hippocampus and the subsynaptic region is depolarized enough, does the calcium ions influx begin immediately and cause LTP. It is commonly believed that such synaptic modifications are involved in memory and learning processes $[1,17,22,28-33,56]$. The basic mechanism for long-term potentiation induction to synapses is the calcium ions influx throughout NMDA channels $[23,35,52,57]$. Such an ionic influx can occur only after removal of magnesium ions blockade of the NMDA channel by enough depolarisation of postsynaptic region. An instant depolarisation of the subsynaptic region depends on the history of inputs patterns, and so any accessory input in any form or shape could potentially enhance the ability to learn. It could be considered as a remote equivalent of the stochastic resonance phenomenon. As a cardinal mechanism involved in the learning process within the nervous tissue, the above should be employed in every complex or simplified neuronal model.

\section{CONCLUSIONS}

The most contemporary interest of medicine is a detailed explanation of course and possibilities for diagnosis and treatment of Alzheimer disease which cause at the late stage complete loss of contemporary memories [21]. And the hippocampo-entorhinal connections are crucial for this disease. At the late end stage the perforant path is completely destroyed. In initial stages, only a few out of thousands of connections from layer 2 stellate cells of entorhinal cortex are disrupted but it always leads to diminished possibilities for learning and memorisation of new cues. And such phenomenon could be easy modelled in presented circuit with enhanced FQ.

In presented circuit we use to model nonlinear dynamic systems an alternative approach to the tra- ditional differential equations. Our presented nonlinear methods are universal and could be used with any binarised time series of data, i.e. for evaluation of changes in heart rhythm [4]. The CA3 model allows modifications of some parameters from various functions and the changing of the cable properties of the dendrite with LSW values. We can also modify input functions so that they collaborate with the receptors in a way as ribbon synapse and use the pyramidal cell of CA3 region for the modelling of ganglion cells [45].

\section{APPENDIX}

\section{Neuronal models of CA3 equations and parameters}

The programme clock step of the presented model equals $0.5 \mathrm{~ms}$ of the simulated real time. First we create tables of shift registers; they form an array of looking up buffer tables. For excitatory inputs (glutamate receptors): AMPA - E (k,i), NMDA - M (k,i), and for inhibitory inputs (GABA receptors): I(k,i) whereas " $\mathrm{k}$ " is the number of the dendritic compartment, " $\mathrm{i}$ " is a number of an area in a particular register table.

Synaptic function - SF(t) calculates, after the arrival of an action potential on a particular synapse, the typical time courses of excitatory or inhibitory postsynaptic potentials (EPSP or IPSP) and futhermore adjusted in term of parameters calculated from functions: Adaptation (2.2) and Memory (2.6) to the appropriate register table. It could be in simply linear form (2.1), but other forms as double exponential alpha function are also possible for use.

$$
S F(t)= \begin{cases}0 & t=t_{s d} \\ \frac{A_{M A X}}{t_{r}}\left(t-t_{s d}\right) & t_{s d}<t \leq t_{r} \\ \frac{A_{M A X}}{t_{d}}\left[\left(t_{d}-\left(t-\left(t_{r}+t_{s d}\right)\right)\right)\right] & t_{r}<t \leq t_{d}\end{cases}
$$

Where: $t_{s d}-$ time of synaptic delay, $t_{r}-$ time of EPSP/IPSP rise, $t_{d}$ - time of EPSP/IPSP decay, 1 millisecond $(\mathrm{ms})=2$ steps of $\mathrm{i}$. Parameters for EPSP $_{\mathrm{AMPA}}$ : $A_{\text {MAX }}=5 \mathrm{mV}, \mathrm{t}_{\mathrm{sd}}=1 \mathrm{~ms}, \mathrm{t}_{\mathrm{r}}=2 \mathrm{~ms}, \mathrm{t}_{\mathrm{d}}=13 \mathrm{~ms}$, for $\operatorname{EPSP}_{\text {NMDA }}: A_{\text {MAX }}=1 \mathrm{mV}, \mathrm{t}_{\mathrm{sd}}=1 \mathrm{~ms}, \mathrm{t}_{\mathrm{r}}=2 \mathrm{~ms}, \mathrm{t}_{\mathrm{d}}=$ $13 \mathrm{~ms}$, and for IPSP $\mathrm{GABA}_{\mathrm{G}}: \mathrm{A}_{\mathrm{MAX}}=-2.5 \mathrm{mV}, \mathrm{t}_{\mathrm{sd}}=1 \mathrm{~ms}$, $\mathrm{t}_{\mathrm{r}}=2 \mathrm{~ms}, \mathrm{t}_{\mathrm{d}}=10 \mathrm{~ms}$.

Adaptation $-A(k, i)$ (for excitatory inputs):

$$
\mathrm{A}(\mathrm{k}, \mathrm{i})=\frac{(\operatorname{ReP}-\mathrm{Rsp})-(\operatorname{ReP}-\mathrm{S}(\mathrm{k}, \mathrm{i}))}{(\operatorname{ReP}-\mathrm{Rsp})}
$$

Where $S(i)$ is the actual value of summarised potential in the k compartment, ReP and Rsp parameters. 
$\mathrm{ReP}=-80 \mathrm{mV}$ (resting potential value), Rsp $=-10 \mathrm{mV}$ (reverse synaptic potential). It presents the possibility of reverse ionic flow through the membrane channels according to the Nernst equation.

Weight of compartment $\mathrm{k}-\mathrm{W}(\mathrm{k})$ (for excitatory inputs):

$$
\mathrm{W}(\mathrm{k})=\frac{1-\mathrm{LSW}}{\mathrm{NE}-1}(\mathrm{k}-\mathrm{NE})+1
$$

Where: LSW, NE - parameters; LSW (low significant weight) - weight of the most distal dendrite input. $\mathrm{NE}=13-$ a number of excitatory inputs. Thus within this function the cable properties of a modelled dendrite could be simply changed.

Function influence $-\operatorname{Inf}(a, b)$ of a compartment on b compartment (for excitatory inputs):

$$
\operatorname{Inf}(a, b)= \begin{cases}1-\frac{1-L S W}{(N-1)} & (a-b) b \geq a \\ 1-\frac{4}{N}(a-b) & (a-b) \leq \frac{N}{4} \\ 0 & \text { otherwise }\end{cases}
$$

$\mathrm{N}=$ total number of inputs and $\mathrm{a}, \mathrm{b} \in \mathrm{N}$. This function allows for the calculation of summarised postsynaptic potential in a particular compartment (2.5) with respect to all others.

Summarised potential - $S(k ; i)$ in compartment $k$ (for excitatory inputs):

$$
\mathrm{S}(\mathrm{k}, \mathrm{i}+\mathrm{1})=\operatorname{ReP}+\sum_{\mathrm{m}=1}^{\mathrm{NE}}(\mathrm{E}(\mathrm{m}, \mathrm{i})-\operatorname{ReP}) \operatorname{Inf}(\mathrm{m}, \mathrm{k})
$$

Where: NE - number of excitatory inputs, Inf $(m, k)$ influence of $m$ - compartment on $k, E(m ; 0)$ the actual value of the appropriate register.

Long-term synaptic potentiation (LTP), called, in short, Memory (Mem):

If $\mathrm{S}(\mathrm{k}, \mathrm{i})>\mathrm{CaMT}$ then

$$
\operatorname{Mem}(\mathrm{k})=1+\ln \frac{\left(\mathrm{C}_{\mathrm{k}}(\mathrm{i})+1\right)}{6 \mathrm{clog}}
$$

CaMT $=-68 \mathrm{mV}$ (threshold for the removal of the $\mathrm{Mg}$ ion block for NMDA channels), $C(k$; i) time of memory for compartment $k$, clog parameter $=2.3026$. If we have simultaneously an action potential on excitatory input and opened NMDA channels due to enough depolarisation of the postsynaptic region (2.5), the LTP induction occurs; the weight of this synapse is being increased. Initiation of the cascade of biochemical reactions, those leading to LTP, depends of amount of calcium ions influenced throughout the opened NMDA channels.
We modelled the pnenomenological event by power function:

$$
\text { power }=\text { powerA }(\mathrm{M}(\mathrm{k} ; \mathrm{i})-\mathrm{ReP})
$$

Whereas powerA $=9$ is a parameter, $M(k ; i)$ - actual value of SF(i) for EPSP(NMDA) in appropriate register.

Time of memory duration $C(k ; i)$ :

$$
\mathrm{C}(\mathrm{k}, \mathrm{i}+1)=\mathrm{C}(\mathrm{k}, \mathrm{i})+\mathrm{e}^{\text {power }}-1
$$

Where: FQ; ReP - parameters. FQ - forgetting coefficient: it decreases, for the next simulation step, the calculated memory time of the programmed value. Clog, powerA, and FQ are numerical parameters, their changes allow confining the strength and time of LTP to biologically plausible values for any kind of modelled neuron.

Input function $(\operatorname{InEx}(k))$ for excitatory and $\ln \operatorname{lnh}(k)$ for inhibitory synapses adds, after the arrival of an action potential (input $>0$ ), the values of the synaptic function (2.1) to the appropriate tables of shift registers $E(k ; i ; t), M(k ; i ; t)$ and $I(k ; i ; t)$, see below (2.9), (2.10) and (2.11). This sum is done with respect to the parameters calculated from functions (2.2) adaptation and (2.6) memory - LTP: thus the other functions are subsequently calculated and the threshold function is proofed.

$$
\begin{gathered}
\mathrm{E}(\mathrm{k} ; \mathrm{i} ; \mathrm{t}+1)=\mathrm{E}(\mathrm{k} ; \mathrm{i} ; \mathrm{t})+\mathrm{A}(\mathrm{k} ; \mathrm{i}) \mathrm{Mem}(\mathrm{k} ; \mathrm{i}) \mathrm{SF}(\mathrm{t}) \\
\mathrm{M}(\mathrm{k} ; \mathrm{i} ; \mathrm{t}+1)=\mathrm{M}(\mathrm{k} ; \mathrm{i} ; \mathrm{t})+\mathrm{SF}(\mathrm{t}) \\
\mathrm{I}(\mathrm{k} ; \mathrm{i} ; \mathrm{t}+1)=\mathrm{I}(\mathrm{k} ; \mathrm{i} ; \mathrm{t})+\mathrm{SF}(\mathrm{t})
\end{gathered}
$$

Summarised postsynaptic potential in neuron (PSP):

$$
\operatorname{PSP}(i+1)=\operatorname{ReP}+\sum_{\mathrm{m}=1}^{\mathrm{NE}} \mathrm{W}(\mathrm{k})\left(\mathrm{E}_{\mathrm{m}, 0}(\mathrm{i})-\mathrm{ReP}\right)+\sum_{\mathrm{m}=1}^{\mathrm{NE}}\left(\mathrm{I}_{\mathrm{m}, 0}(\mathrm{i})-\operatorname{ReP}\right)
$$

Where: $W(k)$ - weight of compartment $k, E(k ; i), I(k ; i)$ are the actual values of the tables from register $E$ and I calculated with (2.9), (2.11), whereas the values of Adaptation (2.2) and Memory (2.6) are from a previous programme step. NE and NI are numbers of excitatory and inhibitory inputs. Threshold function for action potential: threshold $=-50 \mathrm{mV}$ :

$$
\text { out }=\left\{\frac{\text { OPSP }<\text { threshold }}{1 \mathrm{PSP} \geq \text { threshold }}\right.
$$

Refraction is modelled for the time up to $2 \mathrm{~ms}$ by a reset of PSP value (2.11) for inhibitory input registers $\mathrm{I}(\mathrm{k} ; \mathrm{i})$ to the resting potential and shifting the voltage in the register tables $E(k ; i)$ for excitatory inputs according to the: 


$$
\operatorname{ADRV}(\mathrm{k})=\operatorname{ReP}-\frac{(\operatorname{ReP}-\mathrm{RePB})(\mathrm{NE}-\mathrm{k})}{\mathrm{NE}}
$$

ADRV - AntiDromic Reset Voltage function (2.14); RePB is a parameter - voltage to which the most distal dendrite compartment is resetting $(-79 \mathrm{mV})$, ReP $=-80 \mathrm{mV}$. NE - number of excitatory inputs.

Shifting of registers $E$; $M$; l; occurs at the end of each simulation step and the values in all registers tables are shifted as follow (th-threshold):

$$
\begin{aligned}
& \forall_{\mathrm{keN}} \forall_{\mathrm{i} \in(0,31)} \mathrm{E}_{\mathrm{k}, \mathrm{i}}(\mathrm{t}+1)=\left\{\begin{array}{l}
\mathrm{E}_{\mathrm{k}, \mathrm{i}+1}(\mathrm{t}), \text { for PSP }<\text { Threshold } \\
\mathrm{ReP}, \text { for PSP } \geq \text { Threshold }
\end{array}\right. \\
& \forall_{\mathrm{keN}} \forall_{\mathrm{i}(0,31)} \mathrm{M}_{\mathrm{k}, \mathrm{i}}(\mathrm{t}+1)=\left\{\begin{array}{l}
\mathrm{M}_{\mathrm{k}, \mathrm{i}+1}(\mathrm{t}), \text { for PSP }<\text { Threshold } \\
\mathrm{ReP}, \text { for PSP } \geq \text { Threshold }
\end{array}\right. \\
& \forall_{\mathrm{keN}} \forall_{\mathrm{i}(0,31)} \mathrm{I}_{\mathrm{k}, \mathrm{i}}(\mathrm{t}+1)=\left\{\begin{array}{l}
\mathrm{I}_{\mathrm{k}, \mathrm{i}+1}(\mathrm{t}), \text { for PSP }<\text { Threshold } \\
\mathrm{I}_{\mathrm{k}, \mathrm{i}}(\mathrm{t}), \text { for PSP } \geq \text { Threshold }
\end{array}\right.
\end{aligned}
$$

\section{REFERENCES}

1. Andersen $P$, Morris $R$, Amaral R, et al. The Hippocampus Book. 2009, doi: 10.1093/acprof:oso/9780195100273.001.0001, indexed in Pubmed:25246403.

2. Aradi I, Holmes WR. Role of multiple calcium and calciumdependent conductances in regulation of hippocampal dentate granule cell excitability. J Comput Neurosci. 1999; 6(3): 215-235, doi: 10.1023/A:1008801821784, indexed in Pubmed: 10406134.

3. Arleo A, Gerstner W. Spatial cognition and neuro-mimetic navigation: a model of hippocampal place cell activity. Biol Cybern. 2000; 83(3): 287-299, doi:10.1007/s004220000171, indexed in Pubmed: 11007302.

4. Babinec $P$, Kučera $M$, Babincová $M$. Global characterization of time series using fractal dimension of corresponding recurrence plots: from dynamical systems to heart physiology. Harmon Fractal Image Anal. 2005; 1: 87-93.

5. Bienenstock EL, Cooper LN, Munro PW. Theory for the development of neuron selectivity: orientation specificity and binocular interaction in visual cortex. J Neurosci. 1982; 2(1): 32-48, doi: 10.1371/ journal.ppat.0020109, indexed in Pubmed: 7054394.

6. Bliss T, Lømo T. Long-lasting potentiation of synaptic transmission in the dentate area of the anaesthetized rabbit following stimulation of the perforant path. J Physiol. 1973; 232(2): 331-356, doi: 10.1113/jphysiol.1973.sp010273.

7. Boss $B$, Turlejski $K$, Stanfield $B$, et al. On the numbers of neurons on fields CA1 and CA3 of the hippocampus of SpragueDawley and Wistar rats. Brain Res. 1987; 406(1-2): 280-287, doi: 10.1016/0006-8993(87)90793-1.

8. Bragin A, Jandó G, Nádasdy Z, et al. Gamma $(40-100 \mathrm{~Hz})$ oscillation in the hippocampus of the behaving rat. J Neurosci. 1995; 15(1 Pt 1): 47-60, doi:10.1523/jneurosci.4104-10.2010, indexed in Pubmed: 7823151.

9. Brunel N, Trullier O. Plasticity of directional place fields in a model of rodent CA3. Hippocampus. 1998; 8(6): 651-665, doi: 10.1002/ (SICI)1098-1063(1998)8:6\&lt;651::AID-HIPO8\&gt;3.0.CO;2-L, indexed in Pubmed: 9882023.

10. Buzsáki G, Leung LW, Vanderwolf $\mathrm{CH}$. Cellular bases of hippocampal EEG in the behaving rat. Brain Res Rev. 1983; 287(2): 139-171, doi: 0.1016/0165-0173(83)90037-1, indexed in Pubmed: 6357356.

11. Buzsáki G. Two-stage model of memory trace formation: A role for "noisy" brain states. Neuroscience. 1989; 31(3): 551-570, doi: 10.1016/0306-4522(89)90423-5, indexed in Pubmed: 2687720.
12. Buzsáki G. Theta Oscillations in the Hippocampus. Neuron. 2002; 33(3): 325-340, doi: 10.1016/s0896-6273(02)00586-x, indexed in Pubmed:11832222.

13. Cannon R, Hasselmo M, Koene R. From Biophysics to Behavior Catacomb2 and the Design of Biologically-Plausible Models for Spatial Navigation. Neuroinformatics. 2003; 1(1): 003-042, doi: 10.1385/ ni:1:1:003, indexed in Pubmed: 15055391.

14. Cutsuridis V, Graham B, Cobb SR, et al. Hippocampal Microcircuits: A Computational Modelers' Resource Book. 2010, doi: 10.1007/978-1-4419-0996-1, indexed in Pubmed: 8043237.

15. Hasselmo ME, Schnell E, Barkai E. Dynamics of learning and recall at excitatory recurrent synapses and cholinergic modulation in rat hippocampal region CA3. J Neurosci. 1995; 15 (7 Pt 2): 5249-5262, indexed in Pubmed: 7623149.

16. Huerta PT, Lisman JE. Heightened synaptic plasticity of hippocampal CA1 neurons during a cholinergically induced rhythmic state. Nature. 1993; 364(6439): 723-725, doi: 10.1038/364723a0, indexed in Pubmed: 8355787.

17. Jackson MB. Recall of spatial patterns stored in a hippocampal slice by long-term potentiation. J Neurophysiol. 2013; 110(11): $2511-$ 2519, doi:10.1152/jn.00533.2013, indexed in Pubmed: 24027100.

18. Káli S, Dayan P. The involvement of recurrent connections in area CA3 in establishing the properties of place fields: a model. J Neurosci. 2000; 20(19): 7463-7477, indexed in Pubmed: 11007906.

19. Klausberger T, Magill PJ, Márton LF, et al. Brain-state- and celltype-specific firing of hippocampal interneurons in vivo. Nature. 2003; 421(6925): 844-848, doi: 10.1038/nature01374, indexed in Pubmed: 12594513.

20. Klausberger T, Somogyi P. Neuronal diversity and temporal dynamics: the unity of hippocampal circuit operations. Science. 2008; 321(5885): 53-57, doi:10.1126/science.1149381, indexed in Pubmed: 18599766.

21. Llorens-Martin M, Blazquez-Llorca L, Benavides-Piccione R, et al. Selective alterations of neurons and circuits related to early memory loss in Alzheimer's disease. Frontiers Neuroanat. 2014; 8, doi: 10.3389/fnana.2014.00038, indexed in Pubmed: 24904307.

22. Lynch MA. Long-term potentiation and memory. Physiol Rev. 2004; 84(1): 87-136, doi: 10.1152/physrev.00014.2003, indexed in Pubmed: 14715912

23. Marr D. Simple Memory: A Theory for Archicortex. Philos Trans R Soc B Biol Sci. 1971; 262(841): 23-81, doi: 10.1098/ rstb.1971.0078, indexed in Pubmed: 4399412.

24. McClelland JL, Goddard NH. Considerations arising from a complementary learning systems perspective on hippocampus and neocortex. Hippocampus. 1996; 6(6): 654-665, doi: 10.1002/ (SICI)1098-1063(1996)6:6\&lt;654::AID-HIPO8\&gt;3.0.CO;2-G, indexed in Pubmed: 9034852.

25. Migliore $M$, Cook EP, Jaffe DB, et al. Computer simulations of morphologically reconstructed CA3 hippocampal neurons. J Neurophysiol. 1995; 73(3): 1157-1168, doi: 10.1152/jn.1995.73.3.1157, indexed in Pubmed: 7608762.

26. Misják F, Lengyel M, Érdi P. Episodic Memory and Cognitive Map in a Rate Model Network of the Rat Hippocampus. Lecture Notes in Computer Science. 2001: 1135-1140, doi: 10.1007/3-54044668-0_158.

27. Mizuseki K, Sirota A, Pastalkova E, et al. Theta oscillations provide temporal windows for local circuit computation in the entorhinalhippocampal loop. Neuron. 2009; 64(2): 267-280, doi: 10.1016/j. neuron.2009.08.037, indexed in Pubmed: 19874793.

28. Morris RGM. Does synaptic plasticity play a role in information storage in the vertebrate brain? In R. G. M. Morris (Ed.), Parallel distributed processing: Implications for psychology and neurobiology. New York, NY, US: Clarendon Press/Oxford University Press. 1989: 248-285.

29. Morris RGM, Moser El, Riedel G, et al. Elements of a neurobiological theory of the hippocampus: the role of activity-dependent synaptic plasticity in memory. Philos Trans R Soc Lond B Biol Sci. 
2003; 358(1432): 773-786, doi: 10.1098/rstb.2002.1264, indexed in Pubmed: 12744273.

30. Morris RGM. Long-term potentiation and memory. Philos Trans R Soc Lond B Biol Sci. 2003; 358(1432): 643-647, doi: 10.1098/ rstb.2002.1230, indexed in Pubmed: 12740109.

31. Nakazawa K, Quirk MC, Chitwood RA, et al. Requirement for hippocampal CA3 NMDA receptors in associative memory recall. Science. 2002; 297(5579): 211-218, doi: 10.1126/science.1071795, indexed in Pubmed: 12040087.

32. Nakazawa K, Sun L, Quirk M, et al. Hippocampal CA3 NMDA Receptors Are Crucial for Memory Acquisition of One-Time Experience. Neuron. 2003; 38(2): 305-315, doi: 10.1016/s08966273(03)00165-x, indexed in Pubmed: 12718863.

33. Nakazawa K, McHugh TJ, Wilson MA, et al. NMDA receptors, place cells and hippocampal spatial memory. Nat Rev Neurosci. 2004; 5(5): 361-372, doi:10.1038/nrn1385, indexed in Pubmed: 15100719.

34. O'Keefe J, Recce ML. Phase relationship between hippocampal place units and the EEG theta rhythm. Hippocampus. 1993; 3(3): 317-330, doi:10.1002/hipo.450030307, indexed in Pubmed: 8353611.

35. O'Reilly RC, McClelland JL. Hippocampal conjunctive encoding, storage, and recall: avoiding a trade-off. Hippocampus. 1994; 4(6): 661-682, doi:10.1002/hipo.450040605, indexed in Pubmed: 7704110.

36. Poirazi P, Brannon T, Mel B. Arithmetic of subthreshold synaptic summation in a model CA1 pyramidal cell. Neuron. 2003; 37(6): 977-987, doi:10.1016/s0896-6273(03)00148-x, indexed in Pubmed: 12670426.

37. Poirazi P, Brannon T, Mel BW. Pyramidal neuron as two-layer neural network. Neuron. 2003; 37(6): 989-999, doi: 10.1016/S08966273(03)00149-1, indexed in Pubmed: 12670427.

38. Rolls ET, Stringer SM, Trappenberg TP. A unified model of spatial and episodic memory. Proc Biol Sci. 2002; 269(1496): 1087-1093, doi:10.1098/rspb.2002.2009, indexed in Pubmed: 12061949.

39. Rolls E. Cerebral Cortex. Principles of Operation. Oxford University Press, Oxford. 2016.

40. Rolls ET. Pattern separation, completion, and categorisation in the hippocampus and neocortex. Neurobiol Learn Mem. 2016; 129: 4-28, doi:10.1016/j.nlm.2015.07.008, indexed in Pubmed: 26190832.

41. Samsonovich AV. A simple neural network model of the hippocampus suggesting its pathfinding role in episodic memory retrieval. Learn Mem. 2005; 12(2): 193-208, doi: 10.1101/lm.85205, indexed in Pubmed: 15774943.

42. Santhakumar V, Aradi I, Soltesz I. Role of mossy fiber sprouting and mossy cell loss in hyperexcitability: a network model of the dentate gyrus incorporating cell types and axonal topography. J Neurophysiol. 2005; 93(1): 437-453, doi: 10.1152/jn.00777.2004, indexed in Pubmed: 15342722.

43. Saraga F, Wu CP, Zhang L, et al. Active dendrites and spike propagation in multicompartment models of oriens-lacunosum/ moleculare hippocampal interneurons. J Physiol. 2004; 552(3): 673-689, doi: 10.1113/jphysiol.2003.046177, indexed in Pubmed: 12923216 .
44. Shastri L. Episodic memory and cortico-hippocampal interactions. Trends Cogn Sci. 2002; 6(4): 162-168, doi: 10.1016/s13646613(02)01868-5, indexed in Pubmed: 11912039.

45. Sikora MA, Gottesman J, Miller RF. A computational model of the ribbon synapse. J Neurosci Methods. 2005; 145(1-2): 47-61, doi:10.1016/j.jneumeth.2004.11.023, indexed in Pubmed: 15922025

46. Skaggs W, McNaughton B, Wilson M, et al. Theta phase precession in hippocampal neuronal populations and the compression of temporal sequences. Hippocampus. 1996; 6(2): 149-172, doi: 10.1002/ (sici)1098-1063(1996)6:2<149::aid-hipo6>3.0.co;2-k, indexed in Pubmed: 8797016.

47. Squire L. Memory and the hippocampus: A synthesis from findings with rats, monkeys, and humans. Psychol Rev. 1992; 99(2): 195-231, doi:10.1037/0033-295x.99.2.195, indexed in Pubmed: 1594723.

48. Somogyi P, Klausberger T. Defined types of cortical interneurone structure space and spike timing in the hippocampus. J Physiol. 2004; 562(1): 9-26, doi: 10.1113/jphysiol.2004.078915, indexed in Pubmed: 15539390.

49. Somogyi $P$, Katona $L$, Klausberger $T$, et al. Temporal redistribution of inhibition over neuronal subcellular domains underlies statedependent rhythmic change of excitability in the hippocampus. Philos Trans R Soc Lond B Biol Sci. 2014; 369(1635): 20120518, doi: 10.1098/rstb.2012.0518, indexed in Pubmed: 24366131.

50. Stewart M, Fox S. Do septal neurons pace the hippocampal theta rhythm? Trends Neurosci. 1990; 13(5): 163-169, doi: 10.1016/01662236(90)90040-h, indexed in Pubmed: 1693232.

51. Swanson LW, Cowan WM. An autoradiographic study of the organization of the efferent connections of the hippocampal formation in the rat. J Comp Neurol. 1977; 172(1): 49-84, doi: 10.1002/ cne.901720104, indexed in Pubmed: 65364.

52. Treves A, Rolls ET. Computational analysis of the role of the hippocampus in memory. Hippocampus. 1994; 4(3): 374-391, doi:10.1002/hipo.450040319, indexed in Pubmed: 7842058.

53. Tukker JJ, Lasztoczi B, Katona L, et al. Distinct Dendritic Arborization and In Vivo Firing Patterns of Parvalbumin-Expressing Basket Cells in the Hippocampal Area CA3. J Neurosci. 2013; 33(16): 6809-6825, doi: 10.1523/jneurosci.5052-12.2013, indexed in Pubmed: 23595740.

54. Urban NN, Henze DA, Barrionuevo G. Revisiting the role of the hippocampal mossy fiber synapse. Hippocampus. 2001; 11(4): 408-417, doi:10.1002/hipo.1055, indexed in Pubmed: 11530845.

55. Viney TJ, Lasztoczi B, Katona L, et al. Network state-dependent inhibition of identified hippocampal CA3 axo-axonic cells in vivo. Nat Neurosci. 2013; 16(12): 1802-1811, doi: 10.1038/nn.3550, indexed in Pubmed: 24141313.

56. Wang SH, Morris R. Hippocampal-Neocortical Interactions in Memory Formation, Consolidation, and Reconsolidation. Annu Rev Psychol. 2010; 61(1): 49-79, doi: 10.1146/annurev. psych.093008.100523, indexed in Pubmed: 19575620.

57. Willshaw DJ, Buneman OP, Longuet-Higgins HC. Non-holographic associative memory. Nature. 1969; 222(5197): 960-962, doi: 10.1038/222960a0, indexed in Pubmed: 5789326. 